\title{
On-pump versus off-pump surgical revascularization in patients with acute coronary syndromes: Analysis from the Acute Catheterization and Urgent Intervention Triage Strategy trial
}

\author{
Yanai Ben-Gal, MD, ${ }^{a}$ Gregg W. Stone, MD, ${ }^{\mathrm{b}}$ Craig R. Smith, MD, ${ }^{\mathrm{a}}$ Mathew R. Williams, MD, ${ }^{\mathrm{a}, \mathrm{b}}$ \\ Giora Weisz, MD, ${ }^{\mathrm{b}}$ Allan S. Stewart, MD, ${ }^{\mathrm{a}}$ Hiroo Takayama, MD, ${ }^{\mathrm{a}}$ Philippe Genereux, MD, ${ }^{\mathrm{b}}$ and \\ Michael Argenziano, MD
}

Objective: Early invasive strategy, defined as early coronary angiography and subsequent revascularization, when appropriate, is recommended by current guidelines for the management of patients with moderate- to high-risk acute coronary syndromes. We sought to compare the outcomes of patients with acute coronary syndromes undergoing surgical revascularization with an on-pump versus off-pump approach.

\begin{abstract}
Methods: Among a total of 13,819 patients with moderate- to high-risk acute coronary syndromes enrolled in the Acute Catheterization and Urgent Intervention Triage Strategy trial, 1375 patients were triaged to isolated coronary artery bypass grafting. One thousand one hundred fifty-four patients underwent operations with cardiopulmonary bypass (the coronary artery bypass grafting group), and 221 patients underwent off-pump coronary artery bypass grafting (the off-pump coronary artery bypass grafting group). Propensity score matching (1:3) was applied to adjust for differences in baseline clinical and angiographic characteristics, yielding a total of 880 matched patients with acute coronary syndromes (220 managed with off-pump coronary artery bypass grafting and 660 managed with coronary artery bypass grafting).
\end{abstract}

Results: At 30 days, patients undergoing off-pump coronary artery bypass grafting had fewer events of bleeding $(43.7 \%$ vs $56.3 \%, P=.0005)$ and myocardial infarction $(7.3 \%$ vs $12.1 \%, P=.055)$ but higher rates of reintervention $(3.7 \%$ vs $1.2 \%, P=.02)$. At 1 year, there was no difference between groups in death, total myocardial infarctions, reinterventions, strokes, or major adverse cardiac events, but there was a lower rate of non-Q-wave myocardial infarctions in the off-pump coronary artery bypass grafting group $(4.6 \% \mathrm{vs} 9.2 \%, P=.03)$.

Conclusions: In this large-scale study evaluating the outcomes of patients with acute coronary syndromes, offpump coronary artery bypass grafting was associated with lower rates of bleeding and non-Q-wave myocardial infarction but more reinterventions early after the procedure. At 1 year, there was no major outcome difference between the 2 surgical strategies. (J Thorac Cardiovasc Surg 2011;142:e33-9)

Earn CME credits at

http://cme.ctsnetjournals.org

Early invasive strategy, defined as early coronary angiography with subsequent revascularization, when appropriate, results in higher rates of event-free survival than conservative care for patients presenting with moderate- or high-risk acute cor-

\footnotetext{
From the Division of Cardiothoracic Surgery, ${ }^{\text {a }}$ Department of Surgery, College of Physicians and Surgeons, Columbia University Medical Center, New York, NY; and Center for Interventional Vascular Therapy, ${ }^{\mathrm{b}}$ Columbia University Medical Center and the Cardivascular Research Foundation, New York, NY.

Disclosures: Authors have nothing to disclose with regard to commercial support.

Received for publication Oct 21, 2010; revisions received Feb 16, 2011; accepted for publication March 21, 2011; available ahead of print May 2, 2011.

Address for reprints: Yanai Ben-Gal, MD, Columbia University Medical Center, Division of Cardiothoracic Surgery, NY Presbyterian Hospital, College of Physicians \& Surgeons of Columbia University, 177 Fort Washington Ave, MHB 7GN-435, New York, NY 10032 (E-mail: mdbengal@gmail.com). $0022-5223 / \$ 36.00$

Copyright (C) 2011 Published by Elsevier Inc. on behalf of The American Association for Thoracic Surgery

doi:10.1016/j.jtcvs.2011.03.022
}

onary syndromes $(\mathrm{ACSs})^{1}$ and is the recommended approach of the American Heart Association, the American College of Cardiology, and the European Society of Cardiology., The traditional surgical approach of cooling the patient by postponing the surgical procedure in high-risk ACS scenarios to allow stabilization before the operation has been challenged by recent reports validating the positive role of coronary artery bypass grafting $(\mathrm{CABG})$ in patients with ACSs. ${ }^{4-6}$

Although admission to hospitals with an ACS (ie, unstable angina and non-ST-segment elevation myocardial infarction $[\mathrm{MI}])$ is a common and highly frequent occurrence, there are limited data illuminating the superior surgical strategy for these high-risk patients. Of interest are recent reports claiming that off-pump coronary artery bypass grafting (OPCAB) might reduce ischemic injury to the myocardium ${ }^{7-11}$ and suggesting some early benefit for the OPCAB technique after EuroSCORE stratification of patients presenting with active ischemia and unstable angina. ${ }^{12}$

In this report we conducted a subgroup analysis for the outcome of patients with coronary disease who presented with moderate- to high-risk ACSs enrolled in the large-scale 


$$
\begin{aligned}
& \text { Abbreviations and Acronyms } \\
& \begin{aligned}
& \text { ACS }=\text { acute coronary syndrome } \\
& \text { ACUITY= } \text { Acute Catheterization and Urgent } \\
& \text { Intervention Triage Strategy } \\
& \text { CABG }=\text { coronary artery bypass grafting } \\
& \text { CI }=\text { confidence interval } \\
& \text { CPK }=\text { creatine phosphokinase } \\
& \text { MACE }=\text { major adverse cardiac event } \\
& \text { MB }=\text { myocardial band } \\
& \text { MI }=\text { myocardial infarction } \\
& \text { OPCAB }= \text { off-pump coronary artery bypass } \\
& \text { grafting } \\
& \text { OR }=\text { odds ratio } \\
& \text { ULN }=\text { upper limit of normal }
\end{aligned}
\end{aligned}
$$

contemporary Acute Catheterization and Urgent Intervention Triage Strategy (ACUITY) trial with subsequent revascularization by means of either $\mathrm{CABG}$ or OPCAB.

\section{MATERIALS AND METHODS}

The ACUITY trial was a prospective, open-label, randomized, multicenter trial that compared 3 different antithrombotic regimens for patients presenting with moderate- or high-risk ACSs between August 2003 and December 2005 and who were treated with an early invasive strategy. The study design and protocol, as well as its principal results, have been described previously in detail. ${ }^{13}$ In brief, 13,819 patients presenting with non-ST-segment elevation ACSs were randomized to receive unfractionated heparin or enoxaparin with a glycoprotein IIb/IIIa inhibitor, bivalirudin plus a glycoprotein IIb/IIIa inhibitor, or bivalirudin alone. Per protocol, angiographic analysis was intended in all patients within 72 hours of randomization, with subsequent triage to percutaneous coronary intervention, CABG surgery, or medical management.

Inclusion criteria for entering the study were age of 18 years or greater with symptoms of unstable angina lasting 10 minutes or more within 24 hours, with 1 or more of the following criteria: new ST-segment depression or transient elevation of $1 \mathrm{~mm}$ or greater; increased troponin I, troponin $\mathrm{T}$, or creatine kinase-myocardial band (MB) levels; known coronary artery disease; or all 4 other Thrombolysis in Myocardial Infarction risk criteria. ${ }^{14,15}$

Exclusion criteria included acute ST-segment elevation MI or shock, bleeding diathesis or major bleeding within 2 weeks, thrombocytopenia, creatinine clearance of $30 \mathrm{~mL} / \mathrm{min}$ or less, or recent administration of abciximab, warfarin, fondaparinux, fibrinolytic agents, bivalirudin, or more than 1 dose of low-molecular-weight heparin. The study was approved by institutional review boards or ethics committees at each center, and all patients provided written informed consent.

All patients undergoing $\mathrm{CABG}$ received unfractionated heparin as the anticoagulant, with dosing per standard institutional practice. For patients initially randomized to bivalirudin or enoxaparin, the drug was discontinued for at least 1 or 8 hours (if possible) before surgical intervention (for bivalirudin and enoxaparin, respectively). Finally, a 5-day clopidogrel washout period was recommended for patients who received clopidogrel before angiographic analysis and in whom CABG was subsequently planned.

\section{End Points and Definitions}

Prespecified end points were assessed at 30 days and 1 year after the procedure and included death, MI, composite ischemia, unplanned revascularization for ischemia, and combinations of the above defined as composite ischemia (major adverse cardiac events [MACEs]) and were adjudicated by a blinded clinical events committee.

In all patients undergoing $\mathrm{CABG}$, diagnosis of perioperative $\mathrm{MI}$ required the following: (1) any creatine phosphokinase (CPK)-MB level of $10 \times$ or greater of the upper limit of normal (ULN) or CPK of $10 \times$ or greater of the ULN in the absence of MB determination within 24 hours of CABG and increased at least $50 \%$ over the most recent pre-CABG levels or (2) any CPKMB level of $5 \times$ or greater of the ULN (or CPK $\geq 5 \times$ of the ULN in the absence of $\mathrm{MB}$ determination) within 24 hours of $\mathrm{CABG}$ and increased at least $50 \%$ over the most recent pre-CABG levels along with new significant ( $\geq 0.04 \mathrm{~s}) \mathrm{Q}$-waves in 2 or more contiguous electrocardiographic leads.

The somewhat strict ACUITY scale definitions for a bleeding event were as follows: reoperation for bleeding, reduction in hemoglobin concentration of $3 \mathrm{~g} / \mathrm{dL}$ or greater with an overt source of bleeding (or $\geq 4 \mathrm{~g} / \mathrm{dL}$ without), use of any blood product transfusion, and intracranial or intraocular bleeding.

\section{Statistical Analysis}

Continuous variables are summarized as means \pm standard deviations and compared by using 2-sample $t$ tests. Categorical variables are summarized with frequencies and percentages and compared by using $\chi^{2}$ or Fisher's exact tests, where appropriate. Multivariable logistic regression was used to evaluate risk factors for death, MACEs, MI, and reintervention. Odds ratios (ORs) and 95\% confidence intervals (CIs) are given. Event curves for postoperative survival, MACEs, MI, and reintervention are generated by using the Kaplan-Meier method, and comparison between groups is made with the log-rank test. To eliminate all differences between the groups, we further performed a propensity score analysis that was matched for sex, weight, hypertension, ST-segment deviation of $1 \mathrm{~mm}$ or greater, and the number of diseased vessels. The probability (propensity score) that a patient would undergo CABG or OPCAB according to the preprocedural variables was determined by using a saturated logistic regression model to take into account the different patient profiles. Each patient from the OPCAB group was then matched with 3 patients from the CABG group according to their propensity scores, resulting in 880 propensity-matched patients (220 in the OPCAB group and 660 in the CABG group) in whom early and late outcomes were determined.

Categorical variables were compared by using $\chi^{2}$ or Fisher's exact tests. Continuous variables were compared by using the nonparametric Wilcoxon rank sum test. Time-to-event data are displayed by using Kaplan-Meier methodology and were compared with the log-rank test. All analyses were performed with SAS software (SAS Institute, Inc, Cary, NC).

Finally, allocation to treatment group for the present study was made on the basis of the intention to treat. Patients converted during the procedure from the off-pump technique to $\mathrm{CABG}$ with cardiopulmonary bypass were thus included in the OPCAB group.

\section{RESULTS}

Among a total of 13,819 patients with moderate- to highrisk ACSs in the ACUITY trial, a total of $1375(9.9 \%)$ were triaged to isolated CABG. Among these, there were 231 patients who underwent initial operations without the use of cardiopulmonary bypass (the OPCAB group) and 1154 who underwent operations with cardiopulmonary bypass (the CABG group). There was no difference in initial randomization to antithrombotic regimen between the groups, and the initial antithrombotic regimen was included in the multivariable analysis model. There was also no difference between time from study drug cessation to the surgical procedure. All study antiaggregants were discontinued in a timely manner before surgical intervention (Table 1). 
TABLE 1. Randomization for different antithrombotic regimens $(\mathbf{n}=\mathbf{8 8 0})$

\begin{tabular}{lccc}
\hline \multicolumn{1}{c}{ Antithrombotic regimen } & Off pump & On pump & $\boldsymbol{P}$ value \\
\hline Randomized to heparin + IIb/IIIa & $35.0 \%(77 / 220)$ & $35.8 \%(236 / 660)$ & .8710 \\
Randomized to bivalirudin + IIb/IIIa & $35.0 \%(77 / 220)$ & $30.6 \%(202 / 660)$ & .2417 \\
Randomized to bivalirudin alone & $30.0 \%(66 / 220)$ & $33.6 \%(222 / 660)$ & .3615 \\
Time from any study drug stop to CABG (h) & $64.04 \pm 82.59$ & $88.22 \pm 363.32$ & .1338 \\
Time from heparin stop to CABG (h) & $43.89 \pm 65.41$ & $157.12 \pm 898.45$ & .2468 \\
Time from bivalirudin stop to CABG (h) & $64.86 \pm 83.85$ & $75.64 \pm 122.48$ & .2570 \\
Time from bivalirudin +IIb/IIIA stop to CABG $(\mathrm{h})$ & $89.91 \pm 92.47$ & $85.03 \pm 104.24$ & .7320 \\
\hline
\end{tabular}

$C A B G$, Coronary artery bypass grafting.

\section{Results Before Propensity Score Matching}

Patients in the CABG group had more extensive coronary disease, with $2.59 \pm 0.7$ diseased vessels versus $2.44 \pm 0.8$ diseased vessels in the OPCAB group $(P=.007)$; were more likely to present with ST-segment deviation of more than $1 \mathrm{~mm}(51.1 \%$ vs $43.0 \%, P=.03)$; and had a slightly higher body weight $(85.1 \pm 17.6$ vs $82.7 \pm 15.9 \mathrm{~kg}$, $P=.04)$. The complete baseline clinical and angiographic characteristics of the patients are displayed in Table 2.

At 1 month, there was no difference between groups in mortality (3.6\% vs $3.2 \%$, OPCAB vs CABG; $P=.76)$, MI $(7.3 \%$ vs $11.4, \mathrm{OPCAB}$ vs CABG; $P=.07)$, stroke $(0.0 \%$ vs $1.0 \%$, OPCAB vs $\mathrm{CABG} ; P=.23$ ), acute renal injury $(28.2 \%$ vs $31.5 \%$, OPCAB vs CABG; $P=.39)$, or MACEs $(11.3 \%$ vs $14.1 \%$, OPCAB vs CABG; $P=.28)$. Patients undergoing OPCAB had a lower rate of non-Q-wave MI (3.2\% vs $8.0 \%, P=.01)$ and a lower rate of bleeding events ( $43.6 \%$ vs $54.3 \%, P=.001$ ) but required more unplanned coronary reinterventions $(3.6 \%$ vs $1.0 \%, P=.001)$.

\section{Late Outcome}

At 1 year (up to 395 days), there was no difference between the groups in total or cardiac-related mortality, MI, stroke, unplanned reintervention, or MACEs (Table 3).

TABLE 2. Baseline clinical and angiographic characteristics of the study cohort $(\mathbf{n}=1375)$

\begin{tabular}{|c|c|c|c|}
\hline & Off pump $(n=221)$ & On pump $(n=1154)$ & $P$ value \\
\hline Age at randomization $(\mathrm{y})$ & $64.66 \pm 10.59(221)$ & $64.12 \pm 10.17(1154)$ & .47 \\
\hline Male sex & $80.5 \%(178 / 221)$ & $76.3 \%(881 / 1154)$ & .19 \\
\hline Weight $(\mathrm{kg})$ & $82.70 \pm 15.98(221)$ & $85.06 \pm 17.64(1152)$ & .04 \\
\hline Diabetes & $31.4 \%(69 / 220)$ & $34.7 \%(398 / 1146)$ & .35 \\
\hline Insulin diabetes & $11.8 \%(26 / 220)$ & $11.1 \%(127 / 1146)$ & .72 \\
\hline Hypertension & $71.0 \%(157 / 221)$ & $65.6 \%(756 / 1153)$ & .12 \\
\hline Hyperlipidemia & $54.1 \%(118 / 218)$ & $50.7 \%(567 / 1118)$ & .37 \\
\hline Current smoker & $28.3 \%(62 / 219)$ & $27.7 \%(315 / 1136)$ & .87 \\
\hline Previous MI & $24.8 \%(53 / 214)$ & $24.1 \%(274 / 1135)$ & .86 \\
\hline Previous PTCA & $22.7 \%(50 / 220)$ & $21.3 \%(243 / 1143)$ & .65 \\
\hline Previous CABG & $3.6 \%(8 / 221)$ & $4.5 \%(52 / 1153)$ & .72 \\
\hline Renal insufficiency & $22.9 \%(47 / 205)$ & $17.2 \%(186 / 1082)$ & .06 \\
\hline Baseline cardiac biomarker increase & $73.6 \%(153 / 208)$ & $73.9 \%(797 / 1079)$ & .93 \\
\hline Baseline troponin increase & $68.3 \%(136 / 199)$ & $71.4 \%(740 / 1037)$ & .39 \\
\hline ST-segment deviation $\geq 1 \mathrm{~mm}$ & $43.0 \%(95 / 221)$ & $51.1 \%(590 / 1154)$ & .03 \\
\hline $\begin{array}{l}\text { Baseline cardiac biomarker increase or } \\
\text { ST-segment deviation }\end{array}$ & $84.4 \%(178 / 211)$ & $86.5 \%(959 / 1109)$ & .45 \\
\hline \multicolumn{4}{|l|}{ TIMI risk score } \\
\hline Low $(0-2)$ & $11.3 \%(23 / 203)$ & $11.5 \%(119 / 1034)$ & 1.00 \\
\hline Intermediate (3-4) & $51.2 \%(104 / 203)$ & $55.2 \%(571 / 1034)$ & .31 \\
\hline High (5-7) & $37.4 \%(76 / 203)$ & $33.3 \%(344 / 1034)$ & .25 \\
\hline No. of diseased vessels & $2.44 \pm 0.77(221)$ & $2.59 \pm 0.69(1154)$ & .007 \\
\hline LAD disease & $91.0 \%(201 / 221)$ & $93.0 \%(1073 / 1154)$ & .32 \\
\hline LCX disease & $77.8 \%(172 / 221)$ & $82.8 \%(955 / 1154)$ & .08 \\
\hline RCA disease & $75.6 \%(167 / 221)$ & $83.5 \%(964 / 1154)$ & .006 \\
\hline LM disease & $31.7 \%(70 / 221)$ & $31.2 \%(360 / 1154)$ & .87 \\
\hline Multivessel disease & $85.5 \%(189 / 221)$ & $91.1 \%(1051 / 1154)$ & .013 \\
\hline Left ventricular ejection fraction $(\%)$ & $54.01 \pm 12.95(165)$ & $51.86 \pm 13.44(906)$ & .06 \\
\hline
\end{tabular}

$M I$, Myocardial infarction; PTCA, percutaneous transluminal coronary angioplasty; CABG, coronary artery bypass grafting; TIMI, Thrombolysis in Myocardial Infarction; $L A D$, left anterior descending artery; $L C X$, left circumflex artery; $R C A$, right coronary artery; $L M$, left main artery. 
In multivariable analysis we found that 1-month and 1year mortality were not significantly different according to revascularization strategy $(\mathrm{OR}=0.89[95 \% \mathrm{CI}, 0.3-$ 2.67], $P=.98$, and $\mathrm{OR}=1.57$ [95\% CI, 0.74-3.32], $P=.24$, for OPCAB vs CABG at 1 month and 1 year, respectively). However, OPCAB was associated with a significant increase in the rate of early unplanned reinterventions $(\mathrm{OR}=4.1$ [95\% CI, 1.59-10.6], $P=.003)$ and a lower rate of bleeding events (OR $=0.6$ [95\% CI, 0.46-0.84], $P=.002)$.

Of note, 36 patients initially triaged for OPCAB eventually underwent operations with cardiopulmonary bypass. The exact cause of that alteration for each patient was unobtainable, and further study showed that although there were no preoperative differences between patients undergoing "standard" $\mathrm{CABG}$ and those who were converted to CABG (apart from the small difference of a higher percentage of male subjects in the converted group: $91.7 \%$ vs $76.3 \%, P=.028$ ), these patients had higher rates of unplanned reinterventions both early $(8.3 \%$ vs $1.0 \%, P<.0001)$ and late $(11.2 \%$ vs $3.8 \%, P=.02)$ after the procedure compared with patients initially selected for standard CABG strategy. This verifies the notion that improper strategy selection with concomitant conversion from an off-pump to an on-pump procedure has its price.

\section{Results After Propensity Score Matching}

As described in the statistical analysis section, propensity score matching (1:3) was applied to adjust for differences between groups, yielding a total of 880 matched patients with ACSs (220 managed with OPCAB and 660 managed with $\mathrm{CABG}$ ). The baseline clinical and angiographic characteristics of the 2 propensity-matched groups were balanced in all measured characteristics apart from a $6.3 \%$ difference in the extent of right coronary artery disease (Table 4). In the OPCAB group the mean number of grafts per patient was $2.8 \pm 1.2$, whereas in the $\mathrm{CABG}$ group patients had a mean of $3.4 \pm 1.03$ grafts per patient $(P<.0001)$. Exact operative data, such as the type of graft and exact number of vessels treated in the CABG group, could not be generated accurately from the ACUITY database configuration. The mean duration of hospitalization was $13.0 \pm 10.9$ days for the OPCAB group versus $13.0 \pm$ 17 days for the $\mathrm{CABG}$ group $(P<.94)$. There was also no difference in time from procedure to discharge between the groups $(8.9 \pm 10.2$ vs $8.7 \pm 6.8$ days, $\mathrm{OPCAB}$ vs CABG; $P=.79$ ).

At 1 month, there was no difference in all-cause mortality $(3.7 \%$ vs $3.6 \%$, OPCAB vs CABG; $P=.99)$, cardiac mortality, MACEs, stroke rate, and acute renal injury in patients managed with $\mathrm{OPCAB}$ versus $\mathrm{CABG}$. The rates of $\mathrm{MI}$ and bleeding events were higher in the $\mathrm{CABG}$ group $(12.1 \%$ vs $7.3 \%, P=.055$, and $56.3 \%$ vs $43.7 \%$, $P=.0005$, CABG vs OPCAB); however, the rate of
TABLE 3. Early and late clinical outcomes $(n=1375)$

\begin{tabular}{|c|c|c|c|}
\hline & $\begin{array}{c}\text { Off pump } \\
(n=221)\end{array}$ & $\begin{array}{l}\text { On pump } \\
(\mathrm{n}=1154)\end{array}$ & $\begin{array}{c}P \\
\text { value }\end{array}$ \\
\hline \multicolumn{4}{|l|}{ 1-mo Outcomes (to $35 \mathrm{~d}$ ) } \\
\hline Major adverse cardiac events & $11.3 \%(25)$ & $14.1 \%(162)$ & .28 \\
\hline Death/MI & $10.0 \%(22)$ & $13.6 \%(157)$ & .14 \\
\hline Death & $3.6 \%(8)$ & $3.2 \%(37)$ & .76 \\
\hline Cardiac death & $3.6 \%(8)$ & $3.0 \%(35)$ & .65 \\
\hline Noncardiac death & $0.0 \%(0)$ & $0.1 \%(1)$ & .66 \\
\hline MI & $7.3 \%(16)$ & $11.4 \%(131)$ & .07 \\
\hline Q-wave MI & $4.1 \%(9)$ & $3.6 \%(41)$ & .71 \\
\hline Non-Q-wave MI & $3.2 \%(7)$ & $8.0 \%(91)$ & .01 \\
\hline Unplanned revascularization & $3.6 \%(8)$ & $1.0 \%(11)$ & .002 \\
\hline PCI & $2.3 \%(5)$ & $0.7 \%(8)$ & .03 \\
\hline CABG & $1.4 \%(3)$ & $0.3 \%$ & .02 \\
\hline CVA & $0.0 \%(0)$ & $1.0 \%(11)$ & .23 \\
\hline TIA & $0.0 \%(0)$ & $0.3(3)$ & 1.00 \\
\hline Acute renal injury* & $28.2 \%(53)$ & $31.5 \%(323)$ & .39 \\
\hline Bleeding events $\dagger$ & $43.6 \%(96)$ & $54.3 \%(624)$ & .001 \\
\hline Reoperation for bleeding & $0.9 \%(2)$ & $1.1 \%(13)$ & .77 \\
\hline Blood product transfusion & $35.4 \%(78)$ & $41.4 \%(475)$ & .07 \\
\hline \multicolumn{4}{|l|}{ 1-y Outcomes (to $395 \mathrm{~d}$ ) } \\
\hline Major adverse cardiac events & $17.8 \%(39)$ & $18.4 \%(211)$ & .76 \\
\hline Death/MI & $15.1 \%(33)$ & $15.9 \%(182)$ & .69 \\
\hline Death & $6.9 \%(15)$ & $5.3 \%(60)$ & .35 \\
\hline Cardiac death & $4.1 \%(9)$ & $3.8 \%(44)$ & .85 \\
\hline Noncardiac death & $2.9 \%(6)$ & $1.3 \%(14)$ & .08 \\
\hline MI & $9.2 \%(20)$ & $11.8 \%(135)$ & .24 \\
\hline Q-wave MI & $4.1 \%(9)$ & $3.7 \%(42)$ & .75 \\
\hline Non-Q-wave MI & $5.1 \%(11)$ & $8.4 \%(96)$ & .08 \\
\hline Unplanned revascularization & $6.1 \%(13)$ & $3.8 \%(42)$ & .11 \\
\hline PCI & $4.7 \%(10)$ & $3.5 \%(38)$ & .35 \\
\hline CABG & $1.4 \%(3)$ & $0.4 \%(5)$ & .09 \\
\hline CVA & $0.0 \%(0)$ & $1.0 \%(12)$ & .23 \\
\hline TIA & $0.0 \%(0)$ & $0.3(3)$ & 1.00 \\
\hline
\end{tabular}

Rates are displayed as Kaplan-Meier percentage estimates (number of events). $M I$, Myocardial infarction; $P C I$, percutaneous coronary intervention; $C A B G$, coronary artery bypass grafting; $C V A$, cerebrovascular accident; $T I A$, transient ischemic attack. *Denotes a relative $25 \%$ increase or absolute $0.5 \mathrm{mg} / \mathrm{dL}$ increase in serum creatinine values after the procedure compared with baseline values. $\dagger$ Acute Catheterization and Urgent Intervention Triage Strategy (ACUITY) scale definition for bleeding: reoperation for bleeding, reduction in hemoglobin concentration of $3 \mathrm{~g} / \mathrm{dL}$ or greater with an overt source of bleeding (or $\geq 4 \mathrm{~g} / \mathrm{dL}$ without), use of any blood product transfusion, and intracranial/intraocular bleeding.

unplanned repeat revascularization for ischemia was higher in the OPCAB group $(1.2 \%$ vs $3.7 \%, P=.02)$. At 1 year, there was no difference in all propensityadjusted outcomes between the groups apart from nonQ-wave MI rates that were higher in the CABG group $(9.2 \%$ vs $4.6 \%, P=.03)$. The outcomes of the multivariable analysis and propensity score analysis are provided in Table 5 and Figure 1.

\section{DISCUSSION}

An aggressive approach of early angiographic analysis with subsequent revascularization (by means of either 
TABLE 4. Baseline clinical and angiographic characteristics after propensity matching $(1: 3),(n=880)$

\begin{tabular}{|c|c|c|c|}
\hline & Off pump $(n=220)$ & On pump $(n=660)$ & $P$ value \\
\hline Age at randomization (y) & $64.63 \pm 10.61(220)$ & $64.90 \pm 10.30(660)$ & .74 \\
\hline Male sex & $80.5 \%(177 / 220)$ & $82.1 \%(542 / 660)$ & .61 \\
\hline Weight $(\mathrm{kg})$ & $82.72 \pm 16.02(220)$ & $83.47 \pm 15.41(660)$ & .54 \\
\hline Diabetes & $31.5 \%(69 / 219)$ & $34.7 \%(228 / 657)$ & .41 \\
\hline Insulin diabetes & $11.9 \%(26 / 219)$ & $10.2 \%(67 / 657)$ & .52 \\
\hline Hypertension & $70.9 \%(156 / 220)$ & $72.0 \%(475 / 660)$ & .795 \\
\hline Hyperlipidemia & $53.9 \%(117 / 217)$ & $52.9 \%(338 / 639)$ & .81 \\
\hline Current smoker & $28.4 \%(62 / 218)$ & $27.2 \%(177 / 650)$ & .72 \\
\hline Previous MI & $24.9 \%(53 / 213)$ & $25.3 \%(164 / 647)$ & .93 \\
\hline Previous PTCA & $22.8 \%(50 / 219)$ & $22.4 \%(146 / 652)$ & .92 \\
\hline Previous CABG & $3.6 \%(8 / 220)$ & $4.9 \%(32 / 659)$ & .57 \\
\hline Renal insufficiency & $23.0 \%(47 / 204)$ & $18.8 \%(118 / 629)$ & 19 \\
\hline Baseline cardiac biomarker increase & $73.4 \%(152 / 207)$ & $73.9 \%(457 / 618)$ & .92 \\
\hline Baseline troponin increase & $68.3 \%(136 / 199)$ & $71.3 \%(424 / 595)$ & 47 \\
\hline ST-segment deviation $\geq 1 \mathrm{~mm}$ & $42.7 \%(94 / 220)$ & $43.3 \%(286 / 660)$ & .94 \\
\hline Baseline cardiac biomarker increase or ST-segment deviation & $84.3 \%(177 / 210)$ & $84.9 \%(533 / 628)$ & .82 \\
\hline \multicolumn{4}{|l|}{ TIMI risk score } \\
\hline Low $(0-2)$ & $11.4 \%(23 / 202)$ & $10.2 \%(60 / 589)$ & .69 \\
\hline Intermediate (3-4) & $51.5 \%(104 / 202)$ & $54.3 \%(320 / 589)$ & .51 \\
\hline High (5-7) & $37.1 \%(75 / 202)$ & $35.5 \%(209 / 589)$ & .67 \\
\hline No. of diseased vessels & $2.44 \pm 0.77(220)$ & $2.52 \pm 0.75(660)$ & .15 \\
\hline LAD disease & $90.9 \%(200 / 220)$ & $90.8 \%(599 / 660)$ & 1.0000 \\
\hline LCX disease & $77.7 \%(171 / 220)$ & $79.8 \%(527 / 660)$ & .50 \\
\hline RCA disease & $75.5 \%(166 / 220)$ & $81.8 \%(540 / 660)$ & .05 \\
\hline LM disease & $31.8 \%(70 / 220)$ & $32.6 \%(215 / 660)$ & .87 \\
\hline Multivessel disease & $85.5 \%(188 / 220)$ & $88.6 \%(585 / 660)$ & .23 \\
\hline Left ventricular ejection fraction (\%) & $54.01 \pm 12.95(165)$ & $51.79 \pm 13.78(675)$ & .07 \\
\hline
\end{tabular}

See abbreviations in Table 2.

CABG or percutaneous coronary intervention), when appropriate, has been shown to be the superior approach for patients presenting with moderate- to high-risk $\mathrm{ACSs}^{16}$ and is recommended by current US and European guidelines for treating these patients., ${ }^{2,3}$ From the surgical perspective, the traditional convention of cooling off the patient by postponing the procedure during active ischemia has been challenged by a few recent studies. One, a retrospective analysis describing the outcomes of 12,988 unselected patients with ACSs, demonstrated that early CABG (performed in 267 of the patients) was an independent predictor of lower mortality (OR, 0.12). ${ }^{4}$ This report, as well as other communications describing the safety and efficacy of surgical revascularization during ACSs, has reinforced the role of CABG in this setting. ${ }^{5,6}$

Experience with $\mathrm{OPCAB}$ has increased dramatically since the late 1990s, and it has been shown by numerous authors to be safe, reproducible, and effective for patients with coronary artery disease, ${ }^{17,18}$ including those considered to be at high operative risk for various reasons. ${ }^{19,20}$ Although many studies have attempted to identify the potential advantages of off-pump techniques over traditional approaches, most have been undersized or underpowered to detect differences in relevant outcome measures, such as survival, MI, reintervention, or adverse neurologic events.

A recent prospective randomized trial comparing both techniques in a sizeable cohort of 2203 patients (mostly in nonurgent settings) found no difference in 30-day or 1-year mortality between patients undergoing OPCAB and those undergoing $\mathrm{CABG}$, with a lower rate of the 1-year composite outcome of mortality, MI, and reintervention in the CABG group. This was accompanied by a superior graft patency rate in the CABG group among the 1371 patients who underwent follow-up coronary angiographic analysis $(82.6 \%$ vs $87.8 \%$, OPCAB vs CABG; $P<.01) .{ }^{21}$ These results are consistent with a previous, smaller prospective randomized trial evaluating outcomes after off-pump procedures. ${ }^{9}$

In the subpopulation of actively ischemic patients, some speculate that off-pump CABG might reduce the extent of myocardial damage, perhaps through avoidance of ischemic arrest and reperfusion injury, earlier revascularization of the culprit lesion, attenuation of the no-reflow phenomenon, and reduction of myocardial edema. ${ }^{8-11}$ A recent report by Rastan and colleagues ${ }^{7}$ demonstrated that beating-heart techniques implemented during active ischemia reduced in-hospital adverse outcome measures, such as transfusion requirements, extensive inotropic support, prolonged 
TABLE 5. Early and late clinical outcomes for the propensitymatched cohort $(\mathbf{n}=\mathbf{8 8 0})$

\begin{tabular}{|c|c|c|c|}
\hline & $\begin{array}{l}\text { Off pump } \\
(n=220)\end{array}$ & $\begin{array}{l}\text { On pump } \\
(n=660)\end{array}$ & $\begin{array}{c}P \\
\text { value }\end{array}$ \\
\hline \multicolumn{4}{|l|}{ 1-mo Outcomes (to $35 \mathrm{~d}$ ) } \\
\hline Major adverse cardiac events & $11.4 \%(25)$ & $15.5 \%(102)$ & .13 \\
\hline Death/MI & $10.0 \%(22)$ & $14.7 \%(97)$ & .08 \\
\hline Death & $3.7 \%(8)$ & $3.6 \%(24)$ & .99 \\
\hline Cardiac death & $3.7 \%(8)$ & $3.3 \%(22)$ & .83 \\
\hline Noncardiac death & $0.0 \%(0)$ & $0.2 \%(1)$ & .56 \\
\hline MI & $7.3 \%(16)$ & $12.1 \%(79)$ & .055 \\
\hline Q-wave MI & $4.1 \%(9)$ & $3.1 \%(20)$ & .44 \\
\hline Non-Q-wave MI & $3.2 \%(7)$ & $9.0 \%(59)$ & .005 \\
\hline Unplanned revascularization & $3.7 \%(8)$ & $1.2 \%(8)$ & .02 \\
\hline PCI & $2.3 \%(5)$ & $0.8 \%(5)$ & .07 \\
\hline CABG & $1.4 \%(3)$ & $0.5 \%(3)$ & .16 \\
\hline Acute renal injury* & $28.3 \%(53 / 187)$ & $33.3 \%(198 / 594)$ & .21 \\
\hline Bleeding events $\dagger$ & $43.7 \%(96)$ & $56.3 \%(371)$ & .0005 \\
\hline Reoperation for bleeding & $0.9 \%(2)$ & $0.9(6)$ & 1.0 \\
\hline Blood product transfusion & $35.6 \%(78)$ & $42.3(279)$ & .58 \\
\hline CVA & $0.0 \%(0)$ & $1.1 \%(7)$ & .20 \\
\hline TIA & $0.0 \%(0)$ & $0.3 \%(2)$ & 1.0 \\
\hline \multicolumn{4}{|l|}{ 1-y outcomes (to 395 d) } \\
\hline Major adverse cardiac events & $17.4 \%(38)$ & $18.2 \%(120)$ & .69 \\
\hline Death/MI & $14.7 \%(32)$ & $16.2 \%(107)$ & .50 \\
\hline Death & $6.9 \%(15)$ & $5.2 \%(34)$ & .36 \\
\hline Cardiac death & $4.1 \%(9)$ & $4.3 \%(28)$ & .92 \\
\hline Noncardiac death & $2.9 \%(6)$ & $0.8 \%(5)$ & .02 \\
\hline MI & $8.7 \%(19)$ & $12.2 \%(80)$ & .15 \\
\hline Q-wave MI & $4.1 \%(9)$ & $3.1 \%(20)$ & .44 \\
\hline Non-Q-wave MI & $4.6 \%(10)$ & $9.2 \%(60)$ & .03 \\
\hline Unplanned revascularization & $5.6 \%(12)$ & $3.2 \%(20)$ & .09 \\
\hline PCI & $4.2 \%(9)$ & $2.7 \%(17)$ & .25 \\
\hline CABG & $1.4 \%(3)$ & $0.5 \%$ & .16 \\
\hline CVA & $0.0 \%(0 / 220)$ & $1.1 \%(7 / 660)$ & .20 \\
\hline TIA & $0.0 \%(0 / 220)$ & $0.3 \%(2 / 660)$ & 1.0 \\
\hline
\end{tabular}

Rates are displayed as Kaplan-Meier percentage estimates (number of events). See abbreviations in Table 3. * Denotes a relative $25 \%$ increase or absolute $0.5 \mathrm{mg} / \mathrm{dL}$ increase in serum creatinine values after the procedure compared with baseline values. $\dagger$ Acute Catheterization and Urgent Intervention Triage Strategy (ACUITY) scale definition for bleeding: reoperation for bleeding, reduction in hemoglobin concentration of $3 \mathrm{~g} / \mathrm{dL}$ or greater with an overt source of bleeding (or $\geq 4 \mathrm{~g} / \mathrm{dL}$ without), use of any blood product transfusion, and intracranial/intraocular bleeding.

ventilation time, intensive care unit stay, and in-hospital stroke rate. A report by Biancari and associates ${ }^{12}$ evaluated 314 patients with unstable angina, of whom half underwent operations without the use of cardiopulmonary bypass, and found no difference in early or intermediate mortality between the 2 groups $(1.9 \%$ vs $3.9 \%$, OPCAB vs $\mathrm{CABG}$; $P=.33$ ) or in postoperative stroke rate, renal dysfunction, or MACEs. The only difference detected between groups was a lower transfusion requirement in the OPCAB group. Of note, after stratifying patients by their EuroSCORE level, the authors found an apparent early survival and early MACE benefit for those undergoing operations without cardiopulmonary bypass.

In this report we describe the early and midterm clinical outcomes of 1375 patients presenting with moderate- to

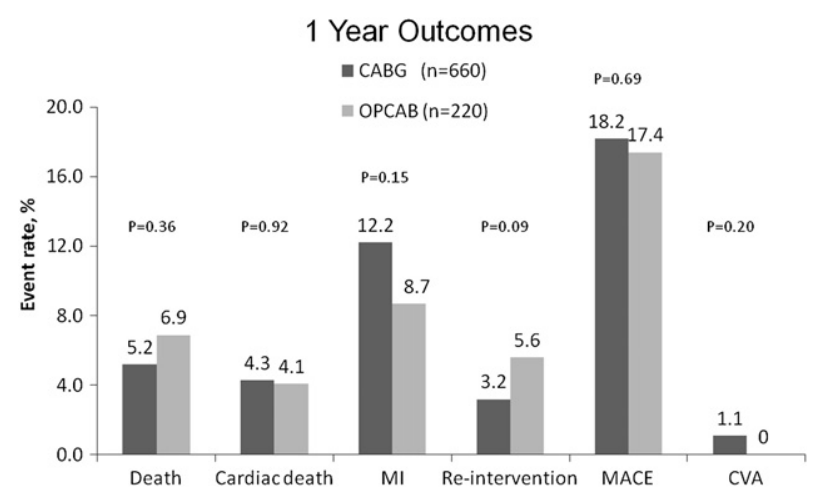

FIGURE 1. One-year outcomes (in percentages) for patients undergoing off-pump coronary artery bypass grafting $(O P C A B)$ and coronary artery bypass grafting $(C A B G)$. $M I$, Myocardial infarction; $M A C E$, major adverse cardiac events; CVA, cerebrovascular accident.

high-risk ACSs who underwent surgical myocardial revascularization with or without cardiopulmonary bypass in the large-scale, contemporary ACUITY trial. The major outcome difference between matched groups was in the early postoperative period, with patients undergoing $\mathrm{OPCAB}$ having lower bleeding events and MI rates and a higher incidence of unplanned coronary reinterventions, whereas at 1 year, patients undergoing $\mathrm{OPCAB}$ had a lower rate of non-Q-wave MIs. In multivariable analysis OPCAB revascularization again was associated with more unplanned early reinterventions. These results are consistent with previous studies performed in various patient populations. ${ }^{8-10,22-24}$ The lower perioperative MI rate might be explained by the minimization of myocardial injury attendant to the avoidance of ischemic arrest, $^{7-10,22}$ whereas the higher reintervention rate might be related either to the more technically demanding nature of performing coronary anastomoses on the beating heart, to the greater tendency to perform incomplete revascularization with this approach, or both. ${ }^{7,25}$

Our study has its limitations, including the fact that patients in the ACUITY trial were randomized to different initial antithrombotic regimens at presentation but not to the surgical approach. Selection of the exact surgical technique and of the revascularization strategy in general was left to the judgment of the clinical investigators and is thus subject to the limitations of selection bias. In addition, because the ACUITY trial was not a surgical trial, some covariates, such as vessel diameter, angiographic appearance, completeness of revascularization, the exact type of graft used or vessels treated, and the surgeon's level of experience, could not be included in the analysis. Finally, the follow-up period of 1 year might not suffice for true evaluation of either surgical strategy.

In conclusion, in this analysis of patients presenting with moderate- to high-risk ACSs and treated with early surgical revascularization, $\mathrm{OPCAB}$ was associated with reduced 
myocardial injury and bleeding, along with more reinterventions early after the procedure. We believe that although these findings are representative of the actual tradeoffs associated with these 2 surgical approaches, they reaffirm the safety and legitimacy of both modalities in these high-risk patients.

\section{References}

1. Mehta SR, Cannon CP, Fox KA, Wallentin L, Boden WE, Spacek R, et al. Routine vs selective invasive strategies in patients with acute coronary syndromes: a collaborative meta-analysis of randomized trials. JAMA. 2005;293: 2908-17.

2. Braunwald E, Antman EM, Beasley JW, Califf RM, Cheitlin MD, Hochman JS, et al. ACC/AHA guideline update for the management of patients with unstable angina and non-ST-segment elevation myocardial infarction-2002: summary article: a report of the American College of Cardiology/American Heart Association Task Force on Practice Guidelines (Committee on the Management of Patients With Unstable Angina). Circulation. 2002;106:1893-900.

3. Bertrand ME, Simoons ML, Fox KA, Wallentin LC, Hamm CW, McFadden E, et al. Management of acute coronary syndromes in patients presenting without persistent ST-segment elevation. Eur Heart J. 2002;23:1809-40.

4. Monteiro P. Impact of early coronary artery bypass graft in an unselected acute coronary syndrome patient population. Circulation. 2006;114(suppl):I467-72.

5. Alexiou K, Kappert U, Staroske A, Joskowiak D, Wilbring M, Matschke K, et al. Coronary surgery for acute coronary syndrome: which determinants of outcome remain? Clin Res Cardiol. 2008;97:601-8.

6. Solodky A, Behar S, Boyko V, Battler A, Hasdai D. The outcome of coronary artery bypass grafting surgery among patients hospitalized with acute coronary syndrome: the Euro Heart Survey of acute coronary syndrome experience. Cardiology. 2005;103:44-7.

7. Rastan AJ, Eckenstein JI, Hentschel B, Funkat AK, Gummert JF, Doll N, et al. Emergency coronary artery bypass graft surgery for acute coronary syndrome: beating heart versus conventional cardioplegic cardiac arrest strategies. Circulation. 2006;114(suppl):I477-85

8. Angelini GD, Taylor FC, Reeves BC, Ascione R. Early and midterm outcome after off-pump and on-pump surgery in beating heart against cardioplegic arrest studies (BHACAS 1 and 2): a pooled analysis of two randomized controlled trials. Lancet. 2002;359:1194-9.

9. Khan NE, deSouza A, Mister R, Flather M, Clague J, Davies S, et al. A randomized comparison of off-pump and on-pump multivessel coronary artery bypass surgery. N Engl J Med. 2004;350:21-8.

10. Van Dijk D, Nierich AP, Jansen EW, Nathoe HM, Suyker WJ, Diephuis JC, et al. Early outcome after off-pump versus on-pump coronary bypass surgery: results from a randomized trial. Circulation. 2001;104:1761-6.

11. D'Ancona G, Karamanoukian H, Kawaguchi AT, Ricci M, Salerno TA, Bergsland J. Myocardial revascularization of the beating heart in high-risk patients. J Card Surg. 2001;16:132-9.
12. Biancari F, Mahar MA, Mosorin M, Heikkinen J, Pokela M, Taskinen P, et al. Immediate and intermediate outcome after off-pump and on-pump coronary artery bypass surgery in patients with unstable angina pectoris. Ann Thorac Surg. 2008; $86: 1147-52$.

13. Stone GW, Bertrand M, Colombo A, Dangas G, Farkouh ME, Feit F, et al. Acute Catheterization and Urgent Intervention Triage strategY (ACUITY) trial: study design and rationale. Am Heart J. 2004;148:764-75.

14. Antman EM, Cohen M, Bernink PJ, McCabe CH, Horacek T, Papuchis G, et al The TIMI risk score for unstable angina/non-ST elevation MI: a method for prognostication and therapeutic decision making. JAMA. 2000;284:835-42.

15. Altman DG, De Stavola BL. Practical problems in fitting a proportional hazards model to data with updated measurements of the covariates. Stat Med. 1994;13: 301-41.

16. Wallentin L, Lagerqvist B, Husted S, Kontny F, Stahle E, Swahn E. Outcome at 1 year after an invasive compared with a non-invasive strategy in unstable coronary-artery disease: the FRISC II invasive randomised trial. FRISC II Investigators. Fast Revascularisation during Instability in Coronary artery disease Lancet. 2000;356:9-16.

17. Puskas J, Cheng D, Knight J, Angelini G, DeCannier D, Diegeler A, et al. Offpump versus conventional coronary artery bypass grafting: a meta-analysis and consensus statement from the 2004 ISMICS consensus conference. Innovations. 2005; 1:3-27.

18. Wijeysundera DN, Beattie WS, Djaiani G, Rao V, Borger MA, Karkouti K, et al. Off-pump coronary artery surgery for reducing mortality and morbidity: metaanalysis of randomized and observational studies. J Am Coll Cardiol. 2005;46 872-82.

19. Oo AY, Grayson AD, Patel NC, Pullan DM, Dihmis WC, Fabri BM. Is off-pump coronary surgery justified in EuroSCORE high-risk cases: a propensity score analysis. Interact Cardiovasc Thorac Surg. 2003;2:660-4

20. Darwazah AK, Abu Sham'a RA, Hussein E, Hawari MH, Ismail H. Myocardia revascularization in patients with low ejection fraction $\leq 35 \%$ : effect of pump technique on early morbidity and mortality. J Card Surg. 2006;21:22-7.

21. Shroyer AL, Grover FL, Hattler B, Collins JF, McDonald GO, Kozora E, et al. On-pump versus off-pump coronary-artery bypass surgery. $N$ Engl $\mathrm{J} \mathrm{Med}$. 2009;361:1827-37

22. Puskas JD, Williams WH, Duke PG, Staples JR, Glass KE, Marshall JJ, et al. Offpump coronary artery bypass grafting provides complete revascularization with reduced myocardial injury, transfusion requirements, and length of stay: a prospective randomized comparison of two hundred unselected patients undergoing off-pump versus conventional coronary artery bypass grafting. J Thorac Cardiovasc Surg. 2003;125:797-808.

23. Subramanian VA, McCabe JC, Geller CM. Minimally invasive direct coronary artery bypass grafting: two-year clinical experience. Ann Thorac Surg. 1997; 64:1648-53.

24. Sabik JF, Gillinov AM, Blackstone EH, Vacha C, Houghtaling PL, Navia J, et al. Does off-pump coronary surgery reduce morbidity and mortality? J Thorac Cardiovasc Surg. 2002;124:698-707.

25. Biancari F, Kangasniemi OP, Luukkonen J, Vuorisalo S, Satta J, Pokela R, et al. EuroSCORE predicts immediate and late outcome after coronary artery bypass surgery. Ann Thorac Surg. 2006;82:57-61. 